\title{
Maternal determinants and fetal outcome of twin pregnancy: a five-year survey
}

\author{
Rachel Mathew ${ }^{1}$, Vinitha Wills ${ }^{1 *}$, Jacob Abraham²
}

\begin{abstract}
${ }^{1}$ Department of Obstetrics and Gynecology, ${ }^{2}$ Department of Pediatrics and Neonatology, Pushpagiri Medical College,
\end{abstract} Thiruvalla, Kerala, India

Received: 25 March 2017

Accepted: 22 April 2017

\section{*Correspondence:}

Dr. Vinitha Wills,

E-mail: drvinithajacob@gmail.com

Copyright: (c) the author(s), publisher and licensee Medip Academy. This is an open-access article distributed under the terms of the Creative Commons Attribution Non-Commercial License, which permits unrestricted non-commercial use, distribution, and reproduction in any medium, provided the original work is properly cited.

\begin{abstract}
Background: Study prevalence of twin pregnancy, maternal risk factors and fetal outcome in twin pregnancy. Methods: A retrospective study of mothers with twin pregnancies who delivered during the period of 5 years. There were 109 mothers who gave birth to 218 babies. Maternal details, antenatal complications and fetal outcomes were analysed.

Results: There were 5432 deliveries which included 109 twin births. Prevalence of twinning was 20/1000 deliveries. The mean age was $28.11( \pm$ SD 4.89$)$ with $69.7 \%$ in the younger age groups. No association with parity, BMI and ovulation induction was found. Most common complication was preterm delivery $(64.2 \%)$ with mean gestational age being 35.07 ( \pm SD 2.32). Others were diabetes (25.7\%), hypertension (22.9\%), hypothyroidism (14.6\%) and postpartum hemorrhage $(13.7 \%)$. Cesarean section was the commonest mode of delivery $(78.0 \%)$ with fetal malpresentation $(26.6 \%)$, fetal distress $(20.2 \%)$ and hypertension $(12.0 \%)$ being the commonest indications for termination. Among the hypertensive mothers, 23 delivered by Cesarean and only 2 delivered vaginally which was statistically significant (p- 0.03 OR 5.20). Dichorionicity was commoner than monochorionicity (66.1\% vs. $33.9 \%)$. Among 218 fetuses delivered, 214 were live births and 4 still born. There were low birth weight Babies (70.6\%), normal weight $(15.3 \%)$, VLBW babies $(11.5 \%)$ and $2.7 \%$ ELBW babies. Fetal complications were IUGR (11.46\%), discordant twins $(6.8 \%)$, congenital anomalies (1.8\%), single fetal demise $(1.8 \%)$ and Intra uterine death of a twin $(0.4 \%)$. Perinatal mortality rate was 1.65 per thousand births.

Conclusions: Prevalence of twin pregnancy was 20/1000 deliveries. Twin pregnancies were seen to be more in the younger age group. Preterm labor, diabetes and hypertension were the main complications with cesarean the most common mode of delivery. Dichorionicity led to less fetal complications and low perinatal mortality.
\end{abstract}

Keywords: Fetal outcome, Maternal risk factors, Twin pregnancy

\section{INTRODUCTION}

Twin pregnancies and higher order gestations are challenges faced by obstetricians globally. The current scenario with increasing use of Artificial Reproductive Techniques (ART) and the increasing maternal age in present day society, is contributing to the increasing trend of multiple pregnancies seen today. ${ }^{1}$ Currently multiple pregnancies account for $32 / 1000(3.2 \%)$ of births globally, though the incidence appears lower in developing countries. ${ }^{2}$

Multiple pregnancies are associated with increase in maternal and perinatal morbidity and mortality. ${ }^{3}$ Twin pregnancies are risk factors during pregnancy as they result in preterm deliveries and are frequently associated with medical complications like preeclampsia, gestational diabetes and antepartum haemorrhage..$^{2,4,5}$ 
Multiple pregnancies also result in poor perinatal outcome due to complications in babies like prematurity, low birth weight, growth restriction and congenital anomalies. Optimizing maternal, fetal and perinatal outcome is definitely a hurdle to be crossed in obstetrics, hence the need for further such studies.

\section{METHODS}

This is a retrospective analysis of all twin pregnancies delivered in the department of Obstetrics and Gynaecology in Pushpagiri Institute of Medical Sciences, Thiruvalla, Kerala, South India over a period of 5 years between $1^{\text {st }}$ July 2010 to June $30^{\text {th }} 2015$.

The study group included 109 pregnant mothers with twin pregnancies who delivered 218 babies including stillborn, in this hospital. All mothers who presented with twin pregnancy in our outpatient department and mothers referred from other peripheral hospitals were included in this study. Mothers with singleton pregnancy and all mothers with higher order pregnancy like triplets were excluded.

Maternal demographic details of patients like age, parity, period of gestation at the time of delivery, history of ovulation induction and family history of twinning was taken. Details of complications that occurred during antenatal period, labour as well as the mode of delivery were collected and analysed.

Data regarding chorionicity and fetal complications were taken. Chorionicity were determined by first trimester ultrasound and confirmed by postnatal placental examination. The total number of babies $(n=218)$ also included those with single fetal demise and intrauterine deaths. Discordance was taken as the inter-twin birth weight difference of $>25 \%$ calculated from the heavier twin. Perinatal mortality rate was also calculated which is the total of early neonatal deaths (less than 7 days of life) and still births per thousand total births (live births plus stills births) which was 1.65 per thousand births.

Information about fetus with congenital malformations, intrauterine growth restrictions and birth weight were collected. Data was analysed and compared with other studies.

\section{Statistical analysis}

The collected data was analysed statistically using SPSS for Windows (version 20.0). Descriptive analysis of data was done using percentage and means. Statistical significance was considered present where $\mathrm{p}$ value was $\leq 0.05$.

\section{RESULTS}

During the period of study, there were 109 twin births among 5432 deliveries giving an overall twinning rate of
20.06 in 1000 deliveries. An analysis of maternal characteristics (Table 1) showed the following details. All mothers were booked cases and the majority (69.72\%) was in the 21-30-year age group. The mean age of the mothers was 28.11 ( \pm SD 4.89 ) years. When we consider gravidity, 56 patients were second gravidas giving a mean gravidity rate of $1.76( \pm$ SD 0.89$)$. Majority of mothers had a pregestational Body Mass Index (BMI) of 25-29 (overweight category) with a mean value of 25.497 $( \pm$ SD 1.9$)$. History of ovulation induction was present in $32.1 \%$ with $40.4 \%$ giving a family history of twinning. Gestational age at the time of delivery ranged from 26-38 weeks of gestation with a mean gestational age of 35.074 $( \pm$ SD 2.319$)$ weeks. A total of $64.21 \%$ of mothers had preterm delivery with $39.44 \%$ patients delivered before 34 weeks.

Table 1: Maternal demographic profile $(n=109)$.

\begin{tabular}{|c|c|c|}
\hline Characteristic & Number & Percent \\
\hline \multicolumn{3}{|c|}{ Maternal age (years) } \\
\hline$\leq 20$ & 1 & 0.9 \\
\hline $21-30$ & 76 & 69.72 \\
\hline $31-40$ & 31 & 28.44 \\
\hline$>40$ & 1 & 0.9 \\
\hline \multicolumn{3}{|l|}{ Gravida } \\
\hline $1^{\text {st }}$ pregnancy & 53 & 48.62 \\
\hline $2^{\text {nd }}$ and above & 56 & 51.37 \\
\hline \multicolumn{3}{|c|}{ Pregestational BMI (kg/m²) } \\
\hline$<18.5$ & 0 & - \\
\hline $18.5-24.9$ & 38 & 34.86 \\
\hline $25-29.9$ & 69 & 62.83 \\
\hline$>29.9$ & 3 & 2.75 \\
\hline \multicolumn{3}{|l|}{ Booked status } \\
\hline Booked & 109 & 100 \\
\hline Unbooked & 0 & - \\
\hline \multicolumn{3}{|c|}{ Period of gestation } \\
\hline$\leq 34$ weeks & 43 & 39.44 \\
\hline 34-37 weeks & 27 & 24.77 \\
\hline$>37$ weeks & 39 & 35.77 \\
\hline \multicolumn{3}{|c|}{ History of ovulation induction } \\
\hline Yes & 35 & 32.11 \\
\hline No & 74 & 67.88 \\
\hline \multicolumn{3}{|c|}{ Family history of twin pregnancy } \\
\hline Yes & 44 & 40.36 \\
\hline No & 65 & 59.63 \\
\hline
\end{tabular}

Antenatal complications (Table 2) like diabetes (25.68\%), hypertension (22.93\%), hypothyroidism (14.67\%) postpartum hemorrhage $(13.76 \%)$ were the common problems. Anaemia was seen in $8.25 \%$ mothers and antepartum hemorrhage occurred only in $4.58 \%$. Only 3 patients $(2.75 \%)$ had cord prolapse.

During the study period, there were no cases of maternal mortality among mothers with twin pregnancies. Cesarean section was the most common mode of delivery (78\%), vaginal delivery occurred in (19\%) while 
combined vaginal-abdominal delivery occurred in $1.8 \%$ cases.

Table 2: Maternal antenatal complications.

\begin{tabular}{|lll|}
\hline Complications & Number & Percent \\
\hline Anemia & 9 & 8.25 \\
\hline Hypertension & 25 & 22.93 \\
\hline Diabetes & 28 & 25.68 \\
\hline Antepartum Hemorrhage & 5 & 4.58 \\
\hline Hypothyroidism & 16 & 14.67 \\
\hline Cord Prolapse & 3 & 2.75 \\
\hline Delayed second stage & 1 & 0.9 \\
\hline Preterm labor $(<37$ weeks) & 70 & 64.22 \\
\hline Postpartum hemorrhage & 15 & 13.76 \\
\hline Puerperal fever & 9 & 8.25 \\
\hline Wound infection & 8 & 7.3 \\
\hline
\end{tabular}

Table 3: Cesarean indications.

Table 4: Medical complications and correlation with mode of delivery.

\begin{tabular}{|c|c|c|c|c|}
\hline Characteristic & LSCS & Vaginal & P Value & OR $(95 \% \mathrm{CI})$ \\
\hline \multicolumn{5}{|l|}{ Anemia } \\
\hline Yes & $6(66.7 \%)$ & $3(33.3 \%)$ & 0.691 & \multirow{2}{*}{$0.667(0.15-2.88)$} \\
\hline No & $69(75 \%)$ & $23(25 \%)$ & & \\
\hline \multicolumn{5}{|l|}{ Hypertension } \\
\hline Yes & $23(92 \%)$ & $2(8.0 \%)$ & 0.032 & \multirow{2}{*}{$5.202(1.13-23.88)$} \\
\hline No & $53(68.8 \%)$ & $24(31.2 \%)$ & & \\
\hline \multicolumn{5}{|c|}{ Diabetes Mellitus } \\
\hline Yes & $21(75 \%)$ & $7(25 \%)$ & 1.000 & \multirow{2}{*}{$1.018(0.37-2.77)$} \\
\hline No & $56(74.7 \%)$ & $19(25.3 \%)$ & & \\
\hline \multicolumn{5}{|c|}{ Antepartum hemorrhage } \\
\hline Yes & $3(60.0 \%)$ & $2(40 \%)$ & 0.601 & \multirow{2}{*}{$0.500(0.07-3.17)$} \\
\hline No & $72(75 \%)$ & $24(25 \%)$ & & \\
\hline
\end{tabular}

Table 5: Factors affecting preterm delivery.

\begin{tabular}{|c|c|c|c|c|}
\hline \multirow{2}{*}{ Factor } & \multicolumn{2}{|l|}{ Preterm } & \multirow{2}{*}{ p value } & \multirow{2}{*}{$\begin{array}{l}\text { Odds Ratic } \\
(95 \%<1)\end{array}$} \\
\hline & Yes & No & & \\
\hline \multicolumn{5}{|l|}{ Age } \\
\hline 31 and above & $16(55.2)$ & $13(44.8)$ & & \multirow{2}{*}{$\begin{array}{l}0.60 \\
(0.25-1.44)\end{array}$} \\
\hline Upto 30 & $51(67.1)$ & $25(32.9)$ & 0.255 & \\
\hline \multicolumn{5}{|l|}{ Gravida } \\
\hline 2 and above & $32(57.1)$ & $24(42.9)$ & & \multirow{2}{*}{$\begin{array}{l}0.54 \\
(0.24-1.24)\end{array}$} \\
\hline Primigravida & $34(70.8)$ & $14(29.2)$ & 0.148 & \\
\hline \multicolumn{5}{|l|}{ Anemia } \\
\hline Yes & $6(66.7)$ & $3(33.3)$ & & \multirow{2}{*}{$\begin{array}{l}1.25 \\
(0.29-5.32)\end{array}$} \\
\hline No & $56(61.5)$ & $35(38.5)$ & 0.762 & \\
\hline \multicolumn{5}{|l|}{ Hypertension } \\
\hline Yes & $16(66.7)$ & $8(33.3)$ & & \multirow{2}{*}{$\begin{array}{l}1.36 \\
(0.49-3.42)\end{array}$} \\
\hline No & $46(60.5)$ & $30(39.5)$ & 0.589 & \\
\hline \multicolumn{5}{|c|}{ Gestational Diabetes } \\
\hline Yes & $20(74.1)$ & 7 (25.9) & & \multirow{2}{*}{$\begin{array}{l}2.06 \\
(0.77-5.4)\end{array}$} \\
\hline No & $43(58.1)$ & $31(41.9)$ & 0.143 & \\
\hline
\end{tabular}

(A $\mathrm{p}$ value $\leq 0.05$ was taken as statistically significant) 
The commonest indication for cesarean delivery was fetal malpresentations $(26.6 \%)$ followed by fetal distress $(20.2 \%)$ and hypertension complicating pregnancy $(12.8 \%)$. Other indications were previous ceserean section $(11 \%)$, abnormalities of labour $(4.6 \%)$, cord prolapse $(4.6 \%)$ and antepartum haemorrhage $(0.9 \%)$ (Table 3).

We analyzed the relation between maternal complications and the mode of delivery (Table 4). Among the hypertensive mothers, 23 were delivered by cesearean while only two vaginally. The difference was statistically significant with a p-value of 0.03 (Odds Ratio 5.202). No statistical significant association between mode of delivery and other medical problems (anemia, diabetes, antepartum hemorrhage) was seen.

Preterm delivery being the most common antenatal complication of twin pregnancy, other factors affecting prematurity were therefore separately analyzed (Table 5). However, there was no statistical significance regarding maternal age, parity, anemia, hypertension or diabetes with preterm delivery.

There were 218 babies among whom 214 were live births and 4 stillborns. When chorionicity was studied, Dichorionic diamniotic (DCDA) twins were more than monochorionic diamniotic (MCDA) twins (66.1\% vs. 29.4\%) (Figure 1).

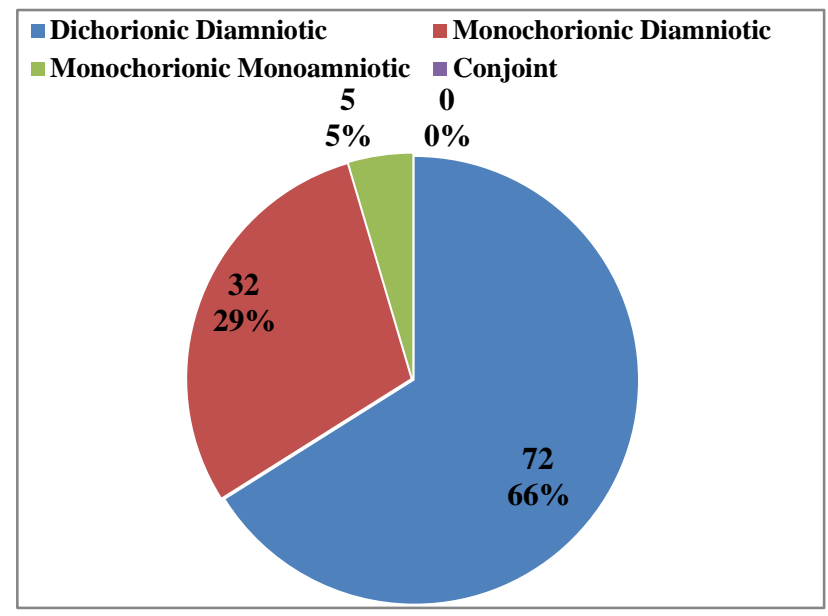

Figure 1: Types of placentation

There were $4.6 \%$ of monochorionic monoamniotic (MCMA) twins and there were no conjoint twins. Cephalic presentation of both babies was seen in $27.5 \%$, cephalic-breech in $22.9 \%$, breech-cephalic in $19.9 \%$, breech-breech in $15.6 \%$ cases and other presentations accounted for $5.6 \%$.

Mean weight of first twin was $2.00( \pm$ SD 0.45) kg while mean weight of the second twin was $1.95( \pm$ SD 0.45) $\mathrm{kg}$. Out of 218 babies under study, majority $(70.6 \%)$ were Low Birth Weight (LBW) [birth weight between $1.5 \mathrm{~kg}$ $2.499 \mathrm{~kg}$ ], $15.3 \%$ were normal weight [Birth weight $\geq$
$2.50 \mathrm{~kg}], 11.46 \%$ were Very Low Birth Weight (VLBW) [weights between $1.00-1.499 \mathrm{~kg}$ ], and $2.75 \%$ were Extremely Low Birth Weight ELBW [birth weight $\leq 999$ grams] (Table 6)

Table 6: Classification of babies according to weight $(n=218)$.

\begin{tabular}{|lll|}
\hline Weight & Number & Percent \\
\hline ELBW & 6 & 2.7 \\
\hline VLBW & 25 & 11.5 \\
\hline LBW & 154 & 70.6 \\
\hline Normal & 33 & 15.1 \\
\hline
\end{tabular}

LBW (Low Birth Weight) -babies <2500g, VLBW (Very Low Birth Weight Babies) -babies <1500gm, ELBW (Extremely Low Birth Weight) -babies $<1000 \mathrm{gm}$, at birth

Among the fetal complications (Table 7) there were $11.46 \%$ Intrauterine Growth Restriction (IUGR) with $6.8 \%$ discordant twins. Other complications like congenital anomalies (1.83\%), single fetal demise $(1.83 \%)$, intrauterine death of both twins $(0.4 \%)$ were observed. Perinatal mortality rate was 1.65 per thousand births.

Table 7: Fetal complications $(n=218)$.

\begin{tabular}{|lll|}
\hline Fetal Complications & Number & Percent \\
\hline Single Fetal Demise & 2 & 0.92 \\
\hline Intra Uterine Fetal Demise $^{\mathrm{a}}$ & 1 & 0.46 \\
\hline Congenital Anomalies & 4 & 1.83 \\
\hline IUGR & 25 & 11.46 \\
\hline Birth weight Discordance & 15 & 6.8 \\
\hline Early neonatal deaths & 5 & 2.29 \\
\hline Late neonatal deaths & 3 & 1.37 \\
\hline
\end{tabular}

\section{DISCUSSION}

Twins and pregnancies of higher order inspite of the advances in perinatal care, are challenges to obstetricians today. This is because of high risk to both the mother and fetus. In India, twin pregnancies complicate $1 \%$ of pregnancies and are the cause of $10 \%$ of perinatal mortality. ${ }^{6-8}$

Though literature reports the prevalence of multiple pregnancies to be influenced mainly by race, heredity and parity, recent trends in developed countries indicates the increase of multiple pregnancy mainly due to delayed child bearing age and artificial reproductive techniques. Our analysis of twin pregnancies over a period of 5 years shows the twinning rate to be $20 / 1000$ deliveries. This high rate is comparable to African studies which reports a high incidence ranging from 20-40/1000 deliveries. ${ }^{9,10}$ This high incidence here could be because the study represents a cross section of high risk pregnancies referred to this tertiary centre with anticipated complications to mother and fetus. All the cases came as 
booked cases. Studies done in India and UK show only an incidence of approximately 10/1000 deliveries. ${ }^{11-13}$

Among the mothers included in this study, majority were in the age between 21-30 years. The mean age of the mothers who participated was $28.11 \pm 4.68$ years. Bassay and Dodd observed a similar mean age in their respective studies. ${ }^{14,15}$ An analysis done by O'Connel over a period of 10 years in the 1990's showed that a maternal age of more than 35 years increased from $0 \%$ to $12.1 \%$ from 1990 to $1999 .{ }^{12}$ However, studies done later in Africa showed more of the mothers belonging to a younger age group. ${ }^{10}$ Race and marriage at a younger age, common in Africa, could have been an influence here.

Present study showed an equal distribution of mothers in the primigravida and multigravida group, though very few mothers had a parity of more than two. All studies independent of racial distribution shows twinning to be associated with increased parity. ${ }^{1}$ O'Connel however observed $59 \%$ in nulliparous with less in multiparous females. ${ }^{12}$ Akaba noticed a higher incidence of twinning in mothers with a parity of 2 as compared nulliparous mothers but also observed in the same study that as parity increased more than 3 , occurrence of twinning was less. ${ }^{10}$

Various theories inferring that increased BMI increases the chance of twinning has been put forth. ${ }^{1}$ In this study, the mean pre-gestational BMI was 25.49 \pm 1.9 (over weight category). However obesity (BMI >30) was seen only in $3 \%$ of mothers. Obese mothers were only $4 \%$ in the research done by Suzuki. ${ }^{16}$

A history of twins in the family was there in $40.4 \%$ of patients in the present study. Yet only $10 \%$ association with family history was found in a study done by Satija et al. ${ }^{11}$ The inadvertent use of ovulation induction drugs and ART has contributed to the rise in higher order of gestation. Ovulation induction was done in $32 \%$ of patients in our study, out of which 3 were In-vitro fertilization pregnancies. High incidence of ART $(47 \%)$ in a Japan ${ }^{16}$ based study and $56 \%$ in a study by Ratha $\mathrm{C}$ et $\mathrm{al}^{17}$ were noted. Satija et al reported only $17.3 \%$ to have had ovulation induction. ${ }^{11}$

All our antenatal cases (100\%) were booked being located in an urban area in Kerala with high literacy rates and good health indices. Many of them were cases referred to us for better obstetric care and neonatal facilities. Timely referral resulted in better maternal and perinatal outcome. Present study included $39.4 \%$ very preterm ( $<34$ weeks), $24.8 \%$ preterm ( $<37$ weeks) and $35.8 \%$ term deliveries respectively. Mean gestational age at the time of delivery was $35.07 \pm 2.3$ weeks. A UK based study showed $50 \%$ of deliveries occurring after 34 weeks with a study in Israel by Laskov also showing $60 \%$ of twin deliveries occurring after 34 weeks, thus reflecting the better antenatal care being offered in developed countries. $^{12,18}$
Multiple pregnancy is associated with greater complications in the mother than in a singleton pregnancy. Preterm delivery was the major problem faced by mothers in this study. $64.22 \%$ of mothers delivered preterm. Majority of cases were spontaneous onset of preterm labour $(27.5 \%)$, preterm premature rupture of membrane $(21 \%)$ and few where terminated for pressing maternal and fetal indications (15.5\%). Medical problems like gestational diabetes $(25 \%)$ and hypertension $(22 \%)$ were the next complications observed in this study. Other complications like anemia (8.25\%), antepartum hemorrhage $(4.58 \%)$, and cord prolapse $(3 \%)$ were also seen. Primary postpartum hemorrhage was seen to have occurred in $13.76 \%$ mothers.

Preterm deliveries were seen to be more in the African population. Nwanko and Akaba observed an incidence of $41 \%$ and $39.7 \%$ respectively. ${ }^{9,10}$ Even studies from Scotland and the United States indicated preterm labour as the most common complications. ${ }^{19}$ Rao et al reported that preterm delivery occurs in 50\% of twins and 10-12\% of preterm deliveries are constituted by twins. ${ }^{3}$

Hypertension is a complication occurring in multiple pregnancies and the risk further increases in monozygotic twins. ${ }^{20,21}$ Hypertension was reported in $46.8 \%$ of women by both Laskov and Buhling. ${ }^{18,22}$ This high incidence seen by Laskov could be because his study group was formed only by women above 45 years. ${ }^{18}$ Inspite of that, he reported Gestational Diabetes only in 20\%. Hypertension $(17 \%)$, anemia $(10 \%)$, postpartum hemorrhage $(11 \%)$ and antepartum hemorrhage $(5 \%)$ were all findings observed by Nwanko et al and was comparable to statistics in our study. ${ }^{9}$

Chorionicity is an important determinant of perinatal outcome in twins. Risks of complications are 15- $20 \%$ more in monochorionic than dichorionic twins. ${ }^{23}$ This study showed a predominance of DCDA twins $(66.1 \%)$, MCDA (29.4\%) and MCMA (4.6\%). Studies by Baghdadi, Ratha C, Hoffman reported DCDA as the majority group in their studies as twins. ${ }^{17,24,25}$

Commonest presentation of twins in our study was cephalic-cephalic (27\%), first twin being cephalic was seen in $55.45 \%$. Even in many other studies conducted in Nigeria, cephalic presentation was the commonest. ${ }^{9,10}$

Many complications are seen to occur during the labour and delivery of twins compared to singleton pregnancies. In spite of the first presentation being cephalic $(55.95 \%)$, $78 \%$ of mothers had to undergo cesarean section. Other associated factors like hypertension, previous cesarean section and fetal distress contributed to this high incidence. Studies in Europe and Africa showed only overall cesarean rate of $50-52 \% .^{9,10,12,24,26} \mathrm{We}$ have observed that pregnancies complicated by twin's cause anxiety to the obstetrician and patient, thus inclining them towards cesarean section. The best method of 
delivery for twins is controversial with some advocating that planned cesarean has a better perinatal outome. ${ }^{27}$

Fetal and perinatal outcome in multiple pregnancy has improved considerably over the years due to the use of tocolytics, steroids, appropriate obstetrical and neonatal care. In this study, among 208 babies, $15.3 \%$ had normal birth weight, $17.6 \%$ had LBW, $11.5 \%$ VLBW and $2.7 \%$ had ELBW. The mean weight of the first twin was 2.00 $( \pm$ SD 0.45$) \mathrm{kg}$ and weight of the second twin was 1.95 $( \pm$ SD 0.62$) \mathrm{kg}$. No significant statistical difference between the birth weight of both babies was seen. A Japanese study by Suzuki reported $67 \%$ babies to be LBW whereas an African study showed $50.3 \%$ to be of normal weight and only $5 \%$ to be LBW. ${ }^{16} \mathrm{VLBW}$ and ELBW babies in that population constituted only $2.5 \%$, showing the racial influence on baby weight.

Other fetal complications that were seen included IUGR $(11.46 \%)$, birth weight discordance $(6.8 \%)$, single fetal demise $(1 \%)$ and congenital anomalies $(1.8 \%)$. These anomalies included omphalocele-meningocele, anterior abdominal wall defect with extrophy of bladder, Diaphragmatic hernia, imperforate anus and hydrocephalus.

Perinatal mortality (1.65/1000 total births) was much less compared to other Indian and African studies. ${ }^{9-11,14}$ Literature supports the fact that complications are fewer in dichorionic than monochorionic twins. Dichorionicity being the majority contributes to the study having less fetal complications and better perinatal outcome. Good neonatal facilities have also helped to attain this good result.

\section{CONCLUSION}

The prevalence of twins in our hospital was 20 per 1000 deiveries. Twins were more common in mothers in the younger age group. Parity and history of ovulation induction were not determining factors. Maternal complications were mainly preterm labour, followed by diabetes and hypertension. Chorionicity was mainly dichorionic with intrauterine growth restriction being the commonest fetal complications. Cesarean section was the main mode of delivery in this study. More vigilance during antenatal period and early reference of twins to tertiary hospital for active fetal surveillance and intervention and appropriate neonatal care can improve fetomaternal outcome.

\section{ACKNOWLEDGMENTS}

Authors would like to thanks Dr. N S Sreedevi, Professor and Head, Department of Obstetrics and Gynaecology, and Dr. Philip Mathew, Assistant Professor, Department of Community Medicine, Pushpagiri Institute of Medical Sciences and Research Centre, Thiruvalla, Kerala, for their support during study.
Funding: No funding sources

Conflict of interest: None declared

Ethical approval: The study was approved by the Institutional Ethics Committee

\section{REFERENCES}

1. Cunningham GF, MacDonald PC, Gant NF, Levano KJ, Gilstrap LC. Multifetal Gestation. In: Williams Obstetrics. $24^{\text {th }}$ ed. Norwalk GT: Appleton and Lange: Ch 45; 2014:891-925.

2. Seshadri L, Arjun G. Multifetal pregnancy. In: Katragada VD, Chauhan P., editors. Essentials of Obstetrics Wolter Kluwer 1st Ed; 2015;32:455-473.

3. Rao A, Sairam S, Shehata H. Obstetric complications of twin pregnancies. Best Pract Res Clin Obstet Gynecol. 2004; 18:557-76.

4. Baxi A, Kaushal M. Outcome of twin pregnancies conceived after assisted reproductive techniques. J Hum Reprod Sci. 2008;1:25-8.

5. Kor-anantakul O, Suwanrath C, Suntharasaj T. Outcome of multifetal pregnancies. J Obstet Gynaecol Res. 2007;33:49-55.

6. Blondel B, Kaminski M. Trends in the occurrence, determinants and consequences of multiple births. Semin Perinatal. 2002;26:239-49.

7. Norwitz ER, Edusa V, Park JS. Maternal Physiology and complications of multiple pregnancy. Semin Perinatol. 2005;29:338-48.

8. Murukesan L, Brahmanandan M. Fetal complications in twin pregnancies with special reference to chorionicity. Academic Med J India. 2015;3(1):13-7.

9. Nwankwo TO, Aniebue UU, Ezenkwele E, Nwafor MI. Pregnancy outcome and factors affecting vaginal delivery of twins at University of Nigeria Teaching Hospital, Enugu. Niger J Clin Pract. 2013;16:490-5.

10. Akaba GO, Agida T E, Onafowokan O, Offiong RA, Adewole ND. Review of twin pregnancies in a tertiary hospital in Abuja, Nigeria. J Health Popul Nutr. 2013;31(2):272-7.

11. Satija M, Sharma S, Soni RK, Sachar RK, Singh GPI. Twinning and its Correlates; CommunityBased study in a Rural Area of India. Bookcomp, Inc.-Wayne State University Press/ Page 611/ 1st proof/ Human Biology 80-6/ December 2008.

12. O' Connell MP, Deo P, Lindow SW. Twin pregnancy in a tertiary referral unit- analysis of trends in the 1990s. J Obstet Gynecol. 2002;22(2):173-4.

13. Manlan G, Scott KE. Contribution of twin pregnancy to perinatal mortality and fetal growth retardation; reversal of growth retardation after birth. CMAJ. 1978;118:365-7.

14. Bassey G, Inimgba NM. Fetomaternal outcome of twin gestation in Port Harcourt, South- South, Nigeria. Niger J Med. 2014;23(4):282-7.

15. Dodd JM, Crowther CA, Haslam RR, Robinson JS. Elective birth at 37 weeks of gestation versus standard care for women with an uncomplicated twin 
pregnancy at term: the twins timing of birth randomised trial. BJOG. 2012;119(8):964-73.

16. Suzuki S. Obstetric Outcomes in Nulliparous women aged 35 and over with dichorionic twin pregnancy. Arch Gynecol Obstet. 2007;276:573-5.

17. Ratha C, Kaul A. An analysis of pregnancy outcome in dichorionic and monochorionic twins given special antenatal and intranatal care, a four year survey. J Obstet Gynaecol India. 2014;64(4):256-9.

18. Laskov L, Michaan N, Cohen A, Tsafir Z, Maslovitz $S$, Kupferminc $M$ et al. Outcome of twin pregnancy in women $\geq 45$ years old; a retrospective cohort study. J Matern Fetal Neonatal Med. 2013;26(7):669-72.

19. Dodd JM, Grievelle RM, Crawther CF. Multiple pregnancy. In: James DK, Steer PJ, Weiner CP, Gonik B. Eds. High risk pregnancies - management options. 4th Ed. Elsevier; 2011:1053-74.

20. Campbell D, MacGilliray L. Preclampsia in twin pregnancies: incidence and outcome. Hypertension Pregnancy. 1999;18:197-207.

21. Monde-Agudel A, Belizan J, Lindmark G. Maternal morbidity and mortality associated with multiple gestations. Obstet Gynecol. 2000;95(6Ptl):899-904.

22. Buhling KJ, Henrich W, Starr E, Lubke M, Bertram $\mathrm{S}$, Siebert $\mathrm{G}$ et al. Risk for gestational diabetes and hypertension for women with twin pregnancy compared to singleton pregnancy. Arch Gynecol Obstet. 2003;269:33-6.
23. Hack KE, Derks JB, Elias SG, Franx A, Roos EJ, Voerman SK et al. Increased perinatal mortality and morbidity in moochorionic versus dichorionic twin pregnancies: Clinical implications of a large Dutch cohort study. BJOG 2008;115(1):58-67.

24. Baghdadi S, Gee H, Whittle MJ, Khan KS. Twin pregnancy outcome and chorionicity. Acta Obstet Gynecol Scand. 2003;82:18-21.

25. Hoffmann E, Oldenburg A, Rode L, Tabor A, Rasmussen S, Skibsted L. Twin Births: cesarean Section or vaginal delivery?. Acta Obstetrica et Gynecologica Scandinavica (C2012 Nordic Federation of Societies of Obstetr Gynecol. 2012;91:463-9.

26. Simoes T, Aboim L, Costa A, Ambroiso A, Alves S, Blickstein I. Puerperal complications following elective cesarean sections for twin pregnancies. J. Perinat. Med. 2007;35:104-7.

27. Mazhar SB, Peerzada A, Mahmud G. Maternal and perinatal complications in multiple versus singleton pregnancies: A prospective two-year study. J Pak Med Assoc. 2002;52:143-7.

Cite this article as: Mathew R, Wills V, Abraham J. Maternal determinants and fetal outcome of twin pregnancy: a five year survey. Int J Reprod Contracept Obstet Gynecol 2017;6:2459-65. 